\title{
ABORDAGEM PARA DISTINGUIR OS EFEITOS DO USO E OCUPAÇÃO DO SOLO NAS CARACTERISTICAS DE BACIAS HIDROGRÁFICAS - UM ESTUDO DE CASO
}

\section{APPROACH TO DISTINGUISH LAND USE AND OCCUPATION EFFECTS ON WATERSHED CHARACTERISTICS - A STUDY CASE}

Roselene Maria Schneider ${ }^{1}$; Rosane Freire ${ }^{2}$; Welliton Leandro de Oliveira Boina; ; Adriana Garcia do Amaral"; Célia Regina Granhen Tavares $^{5}$; Paulo Fernando Soares ${ }^{6}$; Bruno Tiago Contessoto Rigo ${ }^{7}$

${ }^{1,4}$ Docente da Universidade Federal de Mato Grosso - UFMT - Sinop, MT; ${ }^{2}$ Docente da Universidade Estadual Paulista - UNESP - Presidente Prudente, SP; ${ }^{3}$ Engenheiro Ambiental, doutorando pela Universidade Federal de São Carlos - UFSCar, São Carlos, SP; ${ }^{5,6}$ Docente da Universidade Estadual de Maringá - UEM, Maringá, PR; ${ }^{7}$ Geógrafo pela Universidade Estadual de Maringá - UEM, Maringá, PR. e-mail: roselenems@gmail.com

RESUMO - Duas bacias hidrográficas heterogêneas, localizadas na cidade de Maringá-PR, foram avaliadas em relação ao uso e ocupação do solo presente. A bacia do córrego Mandacaru possui área com elevado grau de urbanização (85\%); a bacia do córrego Romeira possui uso e ocupação agrícola. Para a avaliação, utilizou o método dos pinos e realizou a medida de vazão dos canais em estudo. Como resultado verificou-se que a presença de urbanização interfere de forma significativa na estrutura do canal, dada pela erosão de suas margens. Durante o período de acompanhamento (21 meses), o canal urbano apresentou erosão na ordem de centímetros, enquanto o canal agrícola, erosão da ordem de milímetros. Os processos erosivos apresentados pelo canal estiveram diretamente relacionados às altas vazões que ocorreram durante as precipitações. A impermeabilização apresentada pela área da vertente foi responsável pela concentração das águas das chuvas e, portanto, pela energia promotora da erosão medida.

Palavras-chave: escoamento; processo de erosão; urbano e rural.

ABSTRACT - Two heterogeneous hidrological basin, located in Maringá-PR, were evaluated in relation to the use and occupation of its land. The basin of Mandacaru creek owns area with high degree of urbanization (85\%); the basin of Romeira creek owns agricultural use and occupation. For evaluation, were used the method pins and performed the measure of flow channels under study. As result, it has been found that the presence of urbanization interfers significantly on the structure of the channel, given by the erosion of its margins. During the monitoring period (21 months), erosion of the urban channel presented in the order of centimeters, while the rural channel, 
the erosion was in the order of millimeters. Erosive processes presented by the channel were related to high flows that occurred during precipitation. The waterproofing area was responsible for the concentration of rainwater and thus by the energy that promoted the measure erosion.

Keywords: runoff, erosion process, runoff, erosion process, urban and rural.

Recebido em: 11/07/2014

Revisado em: 29/07/2014

Aprovado em: 02/08/2014_ 


\section{INTRODUÇÃO}

Em termos gerais, a água é vista sob três aspectos distintos: um deles diz respeito ao seu controle contra inundações (CEMBRANO et al., 2004; SEMADENI-DAVI et al., 2008; STEVAUX et al., 2009), outro se relaciona à água como um recurso hídrico e, portanto, com seus diferentes usos (CHIEW, 2003; WURBS, 2005; SHARMA; SHAKYA, 2006; UCHEGBU, 2009; GARCÍA-GARIZÁBAL; CAUSAPÉ, 2010 ) e um terceiro, e mais atual, refere-se à água em termos de sua qualidade (MCDOWELL; SRINIVASAN, 2009; TEN VELDHUIS et al., 2010; DU; OTTENS; SLIUZAS, 2010).

Abordando o primeiro aspecto, temse que, muitas vezes, o que se observa em obras urbanas de controle de inundação de grandes centros urbanos é que essas simplesmente aceleram o escoamento da água de um ponto para outro da bacia, sem considerar as características geomorfológicas da região.

Essa abordagem é bastante prática e efetiva do ponto de vista social, uma vez que reduz os riscos de inundações na maior parte dos casos, mas preocupante visto que, a alta velocidade das águas drenadas aumentam a vazão dos canais fluviais durante as precipitações, causando modificações ambientais, tais como processos erosivos nas margens dos canais, assoreamento do leito, transporte de elementos que superam a competência do corpo hídrico (POESEN et al., 2003; ARES; SERRA, 2008; ALEKSEEVSKIY; BERKOVICH; CHALOV, 2008) e a possível mudança do ciclo hidrológico local (OWE, 1985; SAHIN; HALL, 1996; GUO; HU; JIANG, 2008; VILLARINI et al., 2010).

Nas áreas utilizadas para práticas agrícolas, modificações na superfície do solo são realizadas para que se possam introduzir as diferentes culturas. Em geral, a modificação da cobertura do solo modifica a rugosidade deste, fazendo com que haja um aumento ou redução do escoamento superficial em eventos pluviométricos.

Quando a rugosidade é aumentada, pela presença de plantas ou pelo terraceamento, menores cargas de constituintes superficiais do solo podem potencialmente alcançar os rios (SUTTON; FISHER, 2009; CHEN et al., 2009). Considerando regiões com baixas rugosidades (solo exposto), altas velocidades da água são esperadas em eventos de chuva. Dessa forma, todo e qualquer corpo que estiver no caminho da água poderá ser levado das vertentes ao rio.

Com o exposto, este trabalho objetivou apresentar uma comparação entre duas bacias heterogêneas, pertencentes à bacia do ribeirão Maringá-PR, em relação ao uso e ocupação do solo, urbano e rural, avaliando modificações ocorridas nas 
margens dos canais e na vazão específica de base.

\section{METODOLOGIA}

\section{Localização da área de estudo}

A bacia do ribeirão Maringá está localizada no município homônimo, na região norte do estado do Paraná, Brasil, conforme mostra a Figura 1.

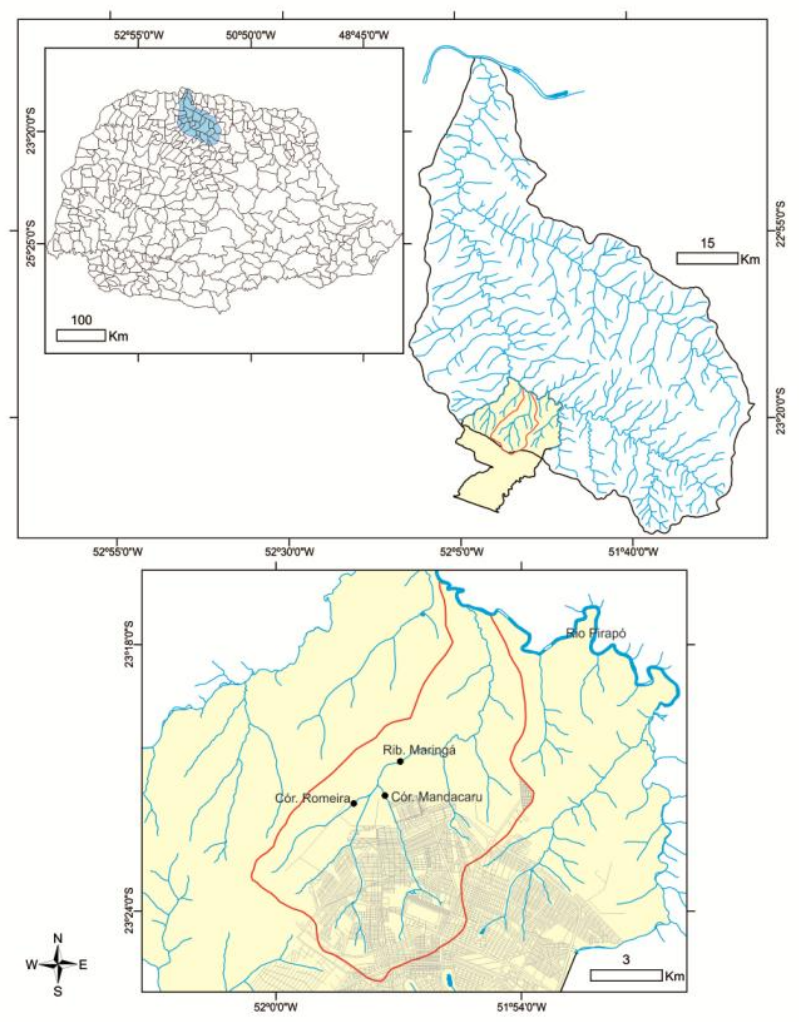

Figura 1. Localização da bacia hidrográfica do ribeirão Maringá

Fonte: Boina, Freire e Schneider (2010)

O clima da região, conforme a classificação de Köppen, é do tipo Cfa com precipitação média anual entre 1.250 a 1.500 $\mathrm{mm}$. O substrato geológico é pertencente à Formação Serra Geral, Grupo São Bento. Geomorfologicamente, a bacia está inserida no Terceiro Planalto Paranaense, apresentando perfil longitudinal com declividade bastante elevada de sua nascente até cerca de um quarto de seu comprimento, mas que reduz drasticamente até a foz; as cotas altimétricas variam de $600 \mathrm{~m}$ a $375 \mathrm{~m}$. Quanto à declividade, os valores variam de até $6 \%$ para os topos, de $6 \%$ a $12 \%$ nas médias vertentes e entre $12 \%$ a $20 \%$ em áreas próximas aos canais de drenagem.

A bacia conta com uma área de drenagem de aproximadamente $90 \mathrm{~km} 2 \mathrm{e}$ seus principais afluentes são os córregos Mandacaru e Romeira. A área de drenagem da bacia do córrego Mandacaru é de cerca de $15 \mathrm{~km} 2$ e o uso do solo é representado por 85\% de área com urbanização consolidada. Há pouquíssimos fragmentos de vegetação densa em Área de Preservação Permanente (APP) e, nas áreas não ocupadas, há agricultura temporária (soja/milho). A bacia do córrego Romeira, localizada no setor oeste, apresenta aproximadamente $8 \mathrm{~km} 2$. Seu uso é restrito às práticas agrícolas e a área apresenta pequenos fragmentos de vegetação densa em APP.

\section{Avaliação da erosão de margem}

Para avaliação das medidas de erosão de margem foi utilizado o método dos pinos (HOOKE, 1980) adaptado para rios de clima tropical (FERNANDES, 1990; ROCHA; SOUZA FILHO, 1996; ROCHA, 2002). O método 
consistiu na inserção de pinos de ferro com 2 $\mathrm{mm}$ de diâmetro e $40 \mathrm{~cm}$ de comprimento nas margens dos canais do córrego Romeira e Mandacaru, conforme mostra a Figura 2.

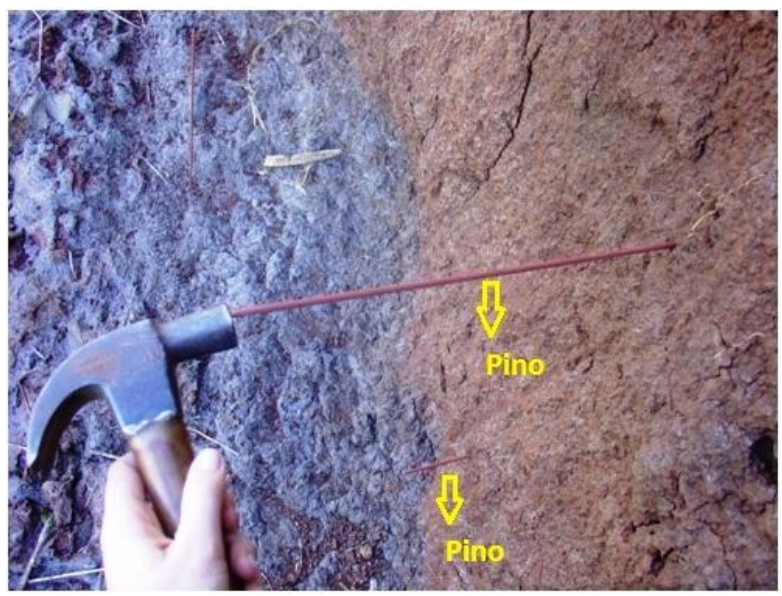

Figura 2. Inserção de pinos de ferro nas margens dos canais Fonte: Schneider (2008)

A inserção dos pinos era realizada da seguinte forma: $30 \mathrm{~cm}$ do pino eram inseridos na margem, deixando-se $10 \mathrm{~cm}$ exposto, como ser verificado na Figura 3.

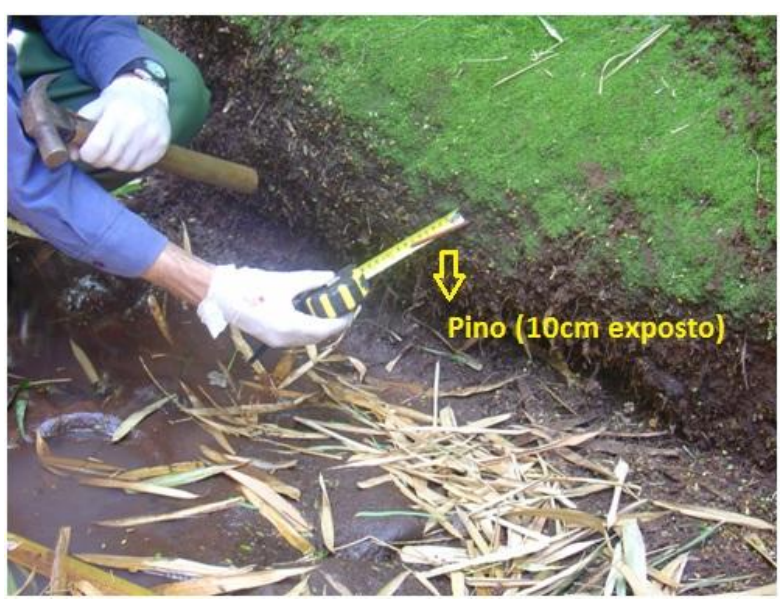

Figura 3. Pinos com $10 \mathrm{~cm}$ exposto nas margens dos canais

Fonte: Schneider (2008)
Após cada evento pluviométrico, a parte exposta era medida e o pino, se necessário, era recolocado ao tamanho inicial, de $10 \mathrm{~cm}$. Assim, a erosão da margem era quantificada pela diferença inicial e final do pino exposto.

Os pinos inseridos nas margens dos canais estudados possuíam um ordenamento chamado de linhas, que também pode ser nomeado como seção. Cada ponto de medição possuía três pinos distribuídos no sentido vertical, em cada margem do canal. Cada região de interesse contava com três linhas, sendo que as distâncias variavam de acordo com a estrutura do barranco. A Figura 4 mostra o esquema da disposição dos pinos em cada ponto de coleta.

Para a avaliação de perda de margem no córrego Mandacaru foram monitorados 7 pontos e no córrego Romeira 2 pontos. $\mathrm{O}$ período de monitoramento, dependendo do ponto, variou de um mês (devido à erosão intensa que removeu os pinos ou roubo dos pinos) a um ano e nove meses de observações.
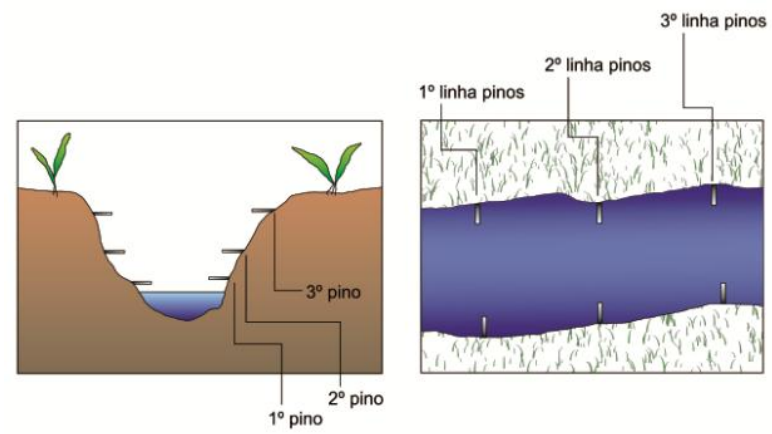

Figura 4. Esquema da disposição dos pinos nas margens dos canais Fonte. Boina (2010) 


\section{Medição da vazão}

As medidas de vazão eram realizadas logo após a medição dos pinos. Todas as determinações eram efetuadas em períodos sem precipitação, portanto, com vazão de base, provinda apenas do reabastecimento subterrâneo dos corpos hídricos.

Em campo, foi utilizado equipamento FlowTracker (YSI/Sontek). A Figura 5 mostra o equipamento montado em uma das margens onde foi realizado medição.
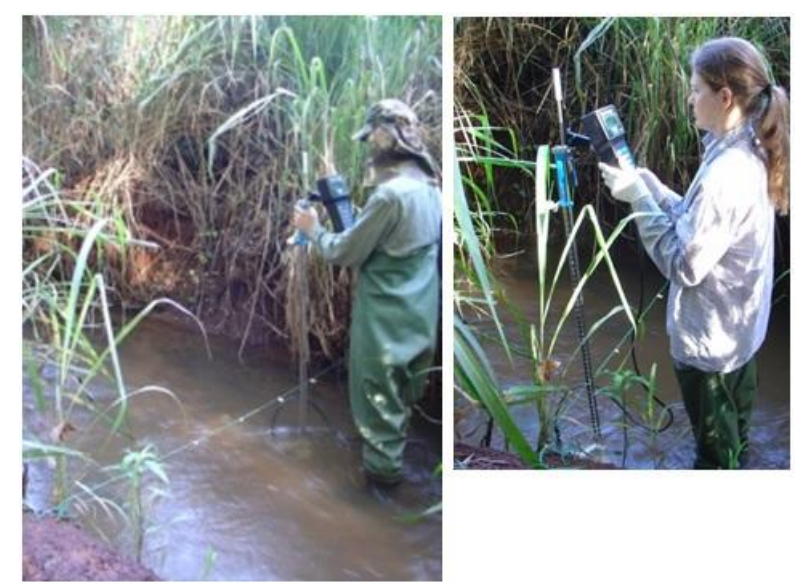

Figura 5. Coleta de dados utilizando FlowTracker (YSI/Sontek) Fonte: Schneider (2008)

A coleta de dados pelo equipamento foi instantânea, contudo houve a necessidade de inserir previamente as características de profundidade e de largura, definindo a seção transversal de cada canal. O modo de coleta de dados foi a seção média e, como esse equipamento possui 0 tratamento estatístico automático, ou seja, foi previamente definido um desvio padrão máximo na média dos dados coletados de
0,01 . As repetições foram realizadas apenas quando o equipamento solicitou uma nova tomada de dados.

Dois pontos de medida da vazão foram distribuídos de acordo com o observado na Figura 1, um no córrego Romeira, CR e outro no córrego Mandacaru, CM.

\section{RESULTADOS}

\section{Degradação dos canais}

Os canais da bacia do Ribeirão Maringá apresentam situações heterogêneas em termos físicos, químicos e biológicos, uma vez que a bacia tem influência tanto de área urbana quanto rural.

Variações temporais significativas da vazão ocorrem em alguns canais da bacia do ribeirão Maringá e foram observadas visualmente durante os trabalhos de campo logo após as precipitações. Estas variações foram evidentes no córrego Mandacaru devido a declividade presente na área de cabeceira e à rápida resposta à precipitação que ocorre em alguns dos canais, em virtude do sistema de galeria drenagem de águas pluviais da malha urbana. Na área agrícola, esta resposta foi significativamente menos pronunciada. Apesar da declividade do relevo da região de cabeceira ser semelhante à bacia anterior, a infiltração da água ocorreu ao longo da vertente. A presença de curva de nível nos plantios e a vegetação marginal 
pouco mais abundante contribuíram para uma resposta distinta do canal aos eventos pluviométricos.

O estudo da perda de margem realizado nos canais dos córregos Mandacaru e Romeira mostrou que as erosões também são bastante diferentes entre si. No canal do córrego Mandacaru, as perdas de solo das margens são maiores do que as perdas de margem no canal do córrego Romeira. Enquanto perdas da ordem de poucos milímetros foram observadas no canal do córrego Romeira, perdas da ordem de muitos centímetros foram observadas no canal do córrego Mandacaru. As práticas conservacionistas presentes na área agrícola do córrego Romeira justificam os resultados encontrados.

Dessa forma, tem-se que na área urbana, os canais naturais são atingidos pela água da chuva de tal maneira que os processos erosivos são favorecidos. A malha urbana faz papel de corredor, direcionando a água da galeria pluvial em direção a canal de drenagem natural. Assim, com o acúmulo de energia potencial e cinética derivados dos escoamentos superficial (malha urbana) e da galeria, o canal distribui toda essa energia ao longo de seu curso.

A forte energia transportada ao longo do curso de água eleva a vazão do corpo hídrico fazendo com que uma grande força seja exercida e ocorra remoção de material de fundo, perda das margens e aumento da competência de transporte.

Como esta força é um agente não natural, ela tende a alterar as condições originais do canal, fazendo com que haja o deslocamento de grandes quantidades de massa de suas margens e transformação do fundo.

Ao contrário do que ocorre no córrego Mandacaru, altas vazões não foram observadas no canal do córrego Romeira. Isto explica o fato dos valores de erosão de margem medidos serem baixos.

No canal do ribeirão Maringá, valores significativos de erosão das margens foram observados, entretanto, menores do que os valores encontrados no canal do córrego Mandacaru. Fato este que pode ser explicado pelo fenômeno da onda de cheia. Sendo o córrego Mandacaru afluente do ribeirão Maringá, a energia causada pela precipitação tende a ser mais elevada no alto e médio córrego, apresentando na sua foz, o declínio de potência e, portanto, menos energia.

Em tempos de grandes desenvolvimento urbanos, ressalta-se que uma situação como essa, observada na bacia do ribeirão Maringá, não é um caso isolado, mas sim relata o caso de muitas outras áreas, inclusive a nível mundial, como aborda Chin (2006) sobre as transformações urbanas em paisagens hídricas num contexto global e sobre um processo evolutivo de pesquisa. 
A redução da perdas de massa dos canais é importante, uma vez que leva a interrupção de vários problemas como o processo de degradação do canal, geração de sedimento e perda de solo agricultável. Os sedimentos gerados contribuem para a contaminação das águas e assoreamento dos canais a jusante, prejudicando o ecossistema aquático.

\section{Avaliação da vazão específica de base}

A comparação das vazões específicas (relação entre vazão e a área de drenagem, em $\mathrm{m}^{3} \cdot \mathrm{h}^{-1} \cdot \mathrm{km}^{-2}$ ) das duas bacias pode ser visualizada na Figura 5. Por meio das medidas realizadas, os valores de vazão específica para ambas as bacias apresentam certa semelhança. Esta semelhança foi confirmada pelo teste de Tukey, que indicou que os valores da vazão específica dos córregos Mandacaru e Romeira não diferem entre si, considerando $5 \%$ de significância.

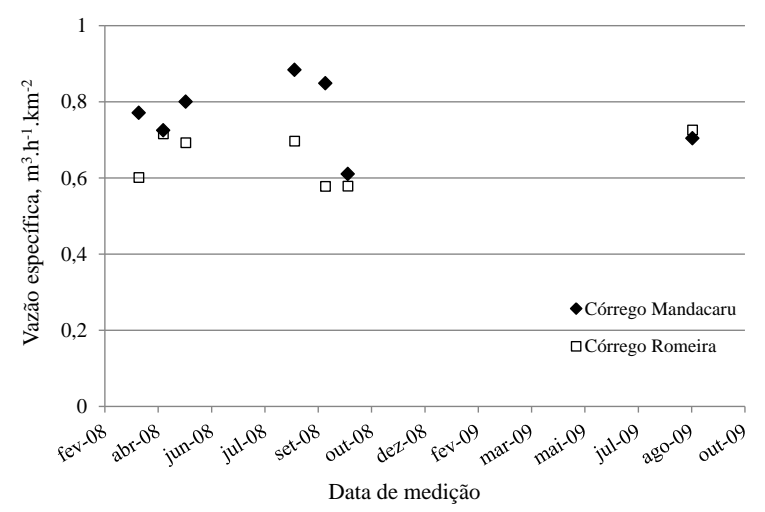

Figura 5. Vazões específicas dos córregos Mandacaru e Romeira Fonte: Schneider (2009)
A tendência de ambas as bacias apresentarem uma vazão específica semelhante, indica que o nível de urbanização, mesmo apresentando-se alto, parece não interferir de forma significativa na quantidade de água que infiltra e percola até o lençol freático, que vai manter o nível de água no córrego. Assim, tem-se que provavelmente outros fatores podem estar contribuindo para a manutenção das vazões de base. Estes fatores podem ser a possibilidade de recarga do lençol freático de bacias adjacentes e até mesmo as contribuições da rede de abastecimento e coleta públicos que apresentam vazamentos de água e de esgoto. Também, em visitas realizadas à área de drenagem, os autores identificaram superfícies da bacia do córrego Mandacaru que não apresentam impermeabilização, mesmo sendo área urbana, permitindo a infiltração de parte da água da chuva.

\section{CONCLUSÃO}

Os efeitos do direcionamento das águas pluviais aos corpos hídricos, se não realizados de forma correta, podem ser bastante onerosos. Processos de recuperação dessas regiões são muitas vezes inviáveis e até mesmo impossíveis de serem realizados.

A presença humana pode não comprometer, a princípio, algumas características da bacia em que estão 
inseridas. Entretanto, é imprescindível que se monitore e avalie potenciais consequências futuras que não possam ser revertidas ou modificadas.

\section{REFERÊNCIAS}

ALEKSEEVSKIY, N. I.; BERKOVICH, K. M.; CHALOV, R. S. Erosion, sediment transportation and accumulation in rivers, International Journal of Sediment Research, v.23, n.2, p.93-105, 2008. http://dx.doi.org/10.1016/S1001$\underline{6279(08) 60009-8}$

ARES, J.; SERRA, J. Selection of sustainable projects for floodplain restoration and urban wastewater management at the lower Chubut River valley (Argentina). Landscape and Urban Planning, v.85, n.3-4, p.215-227, 2008.

http://dx.doi.org/10.1016/i.landurbplan.200

\subsubsection{3}

CEMBRANO, G. et al. Optimal control of urban drainage systems. A case study. Control Engineering Practice, v. 12, n.1, p.19, 2004. http://dx.doi.org/10.1016/S09670661(02)00280-0

CHEN, Su; SUN, Lina; CHAO; CHAO, Lei; ZHOU, Qixing Zhou; SUN, Tieheng. Estimation of Lead Bioavailability in SmelterContaminated Soils by Single and Sequential Extraction Procedure. Bulletin of Environmental Contamination Toxicoly, v. 82, p. 43-47, 2009. http://dx.doi.org/10.1007/s00128-008-9566$\underline{7}$

CHIEW, T. A. Use of seasonal streamflow forecasts in water resources management. Journal of Hydrology, v.270, n.1-2, p.135144, 2003. http://dx.doi.org/10.1016/S00221694(02)00292-5
CHIN, A. Urban transformation of river landscapes in a global context. Geomorphology, v.79, p.460-487, 2006. http://dx.doi.org/10.1016/i.geomorph.2006. $\underline{06.033}$

DU, N.; OTTENS, H.; SLIUZAS, R. Spatial impact of urban expansion on surface water bodies - A case study of Wuhan, China. Landscape and Urban Planning, v.94, n.3-4, p.175-185, 2010. http://dx.doi.org/10.1016/j.landurbplan.200 $\underline{9.10 .002}$

FERNANDES O. V. Q. Mudanças no canal fluvial do Rio Paraná e processos de erosão nas margens: região de Porto Rico (PR). 1990. 96f. Dissertação de mestrado. IGCE/UNESP, Universidade Estadual Paulista, Rio Claro-SP.

GARCÍA-GARIZÁBAL, I.; CAUSAPÉ, J. Influence of irrigation water management on the quantity and quality of irrigation return flows. Journal of Hydrology, v. 385, p. 36-43, 2010.

http://dx.doi.org/10.1016/j.jhydrol.2010.02.0 $\underline{02}$

GUO, H.; HU, Q.; JIANG, T. Annual and seasonal streamflow responses to climate and land-cover changes in the Poyang Lake basin, China. Journal of Hydrology, v.355, n.1-4, p.106-122, 2008. http://dx.doi.org/10.1016/j.jhydrol.2008.03.0 $\underline{20}$

HOOKE, J.M. Magnitude and distribution of rates of river bank erosion. Earth Surface Processes and Landforms, 5, 143-157, 1980. http://dx.doi.org/10.1002/esp.3760050205

MCDOWELL, R. W.; SRINIVASAN, M. S. Identifying critical source areas for water quality: 2. Validating the approach for phosphorus and sediment losses in grazed headwater catchments. Journal of Hydrology, v.379, n.1-2, p.68-80, 2009. 
http://dx.doi.org/10.1016/i.jhydrol.2009.09.0 $\underline{45}$

OWE, M. Long-term streamflow observations in relation to basin development, Journal of Hydrology, v.78, n.3-4, p.243-260, 1985. http://dx.doi.org/10.1016/00221694(85)90104-0

POESEN, J. et al. Gully erosion and environmental change: importance and research needs. CATENA, v.50, n.2-4, p.91133, 2003. http://dx.doi.org/10.1016/S03418162(02)00143-1

ROCHA, P. C. Dinâmica dos canais no sistema rio-planície fluvial do alto rio Paraná, nas proximidades de Porto Rico-PR. 2002. 169f. Tese (Doutorado) - Universidade Estadual de Maringá, Maringá - PR.

ROCHA, P. C.; SOUZA FILHO, E. E. Erosão marginal em canais associados ao

Rio Paraná na região de Porto Rico (PR). Boletim Paranaense de Geociências, 1996.

SAHIN, V.; HALL, M. J. The effects of afforestation and deforestation on water yields, Journal of Hydrology, v.178, n.1-4, p.293-309, 1996.

http://dx.doi.org/10.1016/00221694(95)02825-0

SEMADENI-DAVIES, A.; HERNEBRING, C.; SVENSSON, G.; GUSTAFSSON, L. The impacts of climate change and urbanisation on drainage in Helsingborg, Sweden: Suburban stormwater, Journal of Hydrology, v.350, n.12, p.114-125, 2008. http://dx.doi.org/10.1016/j.jhydrol.2007.11.0 $\underline{06}$

SHARMA, R. H.; SHAKYA, N. M. Hydrological changes and its impact on water resources of Bagmati watershed, Nepal. Journal of Hydrology, v.327, n.3-4, p.315-322, 2006. http://dx.doi.org/10.1016/i.jhydrol.2005.11.0 $\underline{51}$
STEVAUX, J. C. et al. Floods in urban areas of Brazil. Developments in Earth Surface Processes, v.13, p.245-266, 2009. http://dx.doi.org/10.1016/S09282025(08)10013-X

SUTTON, A. J.; FISHER, T. R. Historical changes in water quality at german Branch in choptank river basin. Water, Air and Soil Pollution, v. 199, n. 4, p. 353-369, 2009. http://dx.doi.org/10.1007/s11270-008-9884$\underline{8}$

TEN VELDHUIS J. A. E. et al. Microbial risks associated with exposure to pathogens in contaminated urban flood water. Water Research, v.44, p. 2910-2918, 2010. http://dx.doi.org/10.1016/i.watres.2010.02.0 $\underline{09}$

UCHEGBU, S. N. Effective planning and management as critical factors in urban water supply and management in Umuahia and Aba, Abia State, Nigeria. Physics and Chemistry of the Earth, v.34, n.1-2, p.23-27, 2009.

http://dx.doi.org/10.1016/j.pce.2008.08.004

VILLARINI, G. et al. Radar analyses of extreme rainfall and flooding in urban drainage basins, Journal of Hydrology, v.381, n.3-4, p.266286, 2010. http://dx.doi.org/10.1016/i.jhydrol.2009.11.0 $\underline{48}$

WURBS, R. A. Modeling river/reservoir system management, water allocation, and supply reliability. Journal of Hydrology, v.300, n.1-4, p.100-113, 2005. http://dx.doi.org/10.1016/j.jhydrol.2004.06.0 $\underline{03}$ 